Kenneth R. Carson, Jay R. McDonald, Suhong Luo, and Angelique Zeringue, Research Service, St Louis Veterans Affairs Medical Center; Kenneth R. Carson, Nancy L. Bartlett, Jay R. McDonald, Jingxia Liu, Su-Hsin Chang, and Graham A. Colditz, Washington University School of Medicine; and Qiang Fu, St Louis University School of Public Health, St Louis, MO.

Submitted August 28, 2011; accepted April 11, 2012; published online ahead of print at www.jco.org on May 29, 2012

Supported in part by The BarnesJewish Hospital Foundation, The American Cancer Society Grant No. IRG 58-010-52, and the National Cancer Institute at the National Institutes of Health, Grants No. U54CA155496 and KM1CA15608.

The content of this article is solely the responsibility of the authors and does not necessarily represent the official views of the United States Department of Veterans Affairs, Washington University, Saint Louis University, BarnesJewish Hospital, the American Cancer Society, the National Cancer Institute, or the National Institutes of Health.

Presented in part at the 11th International Conference on Malignant

Lymphoma, Lugano, Switzerland, June 15-18, 2011

Authors' disclosures of potential conflicts of interest and author contributions are found at the end of this article.

Corresponding author: Kenneth R. Carson, MD, Division of Oncology, Washington University School of Medicine, 660 S. Euclid Ave, Campus Box 8056, St Louis, MO 63110; e-mail: kcarson@dom.wustl.edu.

(C) 2012 by American Society of Clinical Oncology

0732-183X/12/3026-3217/\$20.00

DOI: $10.1200 / J C O .2011 .39 .2100$

\title{
Increased Body Mass Index Is Associated With Improved Survival in United States Veterans With Diffuse Large B-Cell Lymphoma
}

Kenneth R. Carson, Nancy L. Bartlett, Jay R. McDonald, Suhong Luo, Angelique Zeringue, Jingxia Liu, Qiang Fu, Su-Hsin Chang, and Graham A. Colditz

$$
\begin{array}{llllllll}
\text { A } & \text { B } & \text { S } & \text { T } & \text { R } & \text { A } & \text { C } & \text { T }
\end{array}
$$

\section{Purpose}

Obesity increases the risk of death from many malignancies, including non-Hodgkin's lymphoma $(\mathrm{NHL})$. In diffuse large B-cell lymphoma (DLBCL), the most common form of NHL, the association between body mass index (BMI) at diagnosis and survival is unclear.

\section{Patients and Methods}

We evaluated the association between BMI at diagnosis and overall survival in a retrospective cohort of 2,534 United States veterans diagnosed with DLBCL between October 1, 1998 and December 31, 2008. Cox modeling was used to control for patient- and disease-related prognostic variables.

\section{Results}

Mean age at diagnosis was 68 years (range, 20 to 100 years); 64\% of patients were overweight (BMI, 25 to $<30)$ or obese (BMI, $\geq 30)$. Obese patients were significantly younger, had significantly fewer B symptoms, and trended toward lower-stage disease, compared with other BMI groups. Cox analysis showed reduced mortality in overweight and obese patients (overweight: hazard ratio $[\mathrm{HR}], 0.73 ; 95 \% \mathrm{Cl}, 0.65$ to 0.83 ; obese: $\mathrm{HR}, 0.68 ; 95 \% \mathrm{Cl}, 0.58$ to 0.80 ), compared with normal-weight patients $(\mathrm{BMI}, 18.5$ to $<25)$. Treatment during the rituximab era reduced the risk of death without affecting the association between BMI and survival. Diseaserelated weight loss occurred in $29 \%$ of patients with weight data 1 year before diagnosis. Cox analysis based on BMI 1 year before diagnosis continued to demonstrate reduced risk of death in overweight and obese patients.

\section{Conclusion}

Being overweight or obese at the time of DLBCL diagnosis is associated with improved overall survival. Understanding the mechanisms responsible for this association will require further study.

\section{J Clin Oncol 30:3217-3222. (C) 2012 by American Society of Clinical Oncology}

\section{INTRODUCTION}

Two thirds of the adult population in the United States is overweight or obese. ${ }^{1}$ Multiple studies associate Body Mass Index (BMI) greater than 25 $\mathrm{kg} / \mathrm{m}^{2}$ with increased mortality. ${ }^{2,3}$ Many of those obesity-related deaths are as a result of cancer., ${ }^{4,5}$ Elevated BMI increases cancer-specific death either through increased cancer incidence, decreased survival after diagnosis, or both. ${ }^{5} \mathrm{Al}$ though there is extensive literature evaluating obesity and cancer incidence, fewer studies examine the impact of obesity on survival after cancer diagnosis. ${ }^{6}$ Improved understanding of the relationship between BMI and outcome is clinically relevant because obesity may influence chemotherapy dosing decisions. ${ }^{7}$ Obesity also serves as a measure of baseline energy balance, which is influenced by diet and exercise, both of which can impact outcomes in patients with solid and hematologic malignancies. ${ }^{8-11}$

In breast and colon cancer, increased BMI at time of diagnosis is associated with an increased risk of disease recurrence and death. ${ }^{12,13}$ Hypothesized reasons for the poorer prognosis in obese patients include differences in tumor biology, hormonal balance, metabolism, or treatment efficacy. ${ }^{14-16}$ Empiric chemotherapy dose reduction in obese patients, as a result of concerns about toxicities associated with high absolute chemotherapy doses, may also be important. ${ }^{7,17}$ In contrast, increased BMI at the time of diagnosis is associated with improved survival in patients with organlimited renal cell carcinoma and lung cancers. ${ }^{18,19}$ 
Previous literature evaluating the influence of BMI on survival in patients with lymphoma has produced mixed results. In Hodgkin's lymphoma, one small study associated greater adiposity with improved survival. ${ }^{20}$ Whereas in non-Hodgkin's lymphoma (NHL), one study found that obesity decreased survival and another found improved survival in overweight but not obese patients. ${ }^{21,22}$ Similar mixed results have been found in lymphoma patients receiving autologous stem-cell transplantation. ${ }^{23,24}$ The lack of objective weight measurements before diagnosis and the classification of lymphoma or NHL as a single disease entity represent major limitations of most previous studies. To clarify the relationship between obesity and the most common form of NHL, diffuse large B-cell lymphoma (DLBCL), we examined the relationship between BMI and overall survival in a cohort of patients diagnosed with DLBCL within the United States Veterans Health Administration (VHA) hospital system.

\section{PATIENTS AND METHODS}

\section{Study Cohort}

This study was approved by the Saint Louis VHA Medical Center and Washington University School of Medicine institutional review boards before the study cohort was identified. Patients with DLBCL diagnosed between October 1, 1998 and December 31, 2008 were identified in the VHA central cancer registry. Records of 3,227 patients with DLBCL (International Classification of Diseases [ICD] -O3 code 9680) or immunoblastic lymphoma (ICD-O3 code 9684) were identified, consistent with the InterLymph classification system. ${ }^{25}$ Data were obtained from all 21 regional VHA districts throughout the United States.

Individual patient records were linked to additional information on vital status, vital signs (including weight and height), and ICD-9 codes for comorbid conditions. Electronic medical records were examined to fill in missing data, when available, using the Compensation and Pension Records Interchange software system. After completion of electronic medical record review, patients with missing information on comorbidities, vital status, or with inadequate histologic confirmation of DLBCL were excluded $(n=26)$. Patients testing positive for HIV or with CNS involvement were also excluded $(\mathrm{n}=239)$. Finally, patients without weight measurement at time of DLBCL diagnosis were also excluded $(n=428)$. This resulted in a primary study cohort of 2,534 (79\%) of 3,227 with a new diagnosis of DLBCL during the study timeframe. For further details, see the CONSORT diagram (Fig 1).

\section{Measurements and Definitions}

BMI was calculated as weight measured in kilograms divided by the square of height measured in meters $\left(\mathrm{kg} / \mathrm{m}^{2}\right)$. Consistently recorded height data from any time in the clinical history was considered accurate. Weight at diagnosis was defined as weight measured closest to, but within 1 month of DLBCL diagnosis date. Historical weight was defined as weight measured closest to, but within 3 months of the date 1 year before DLBCL diagnosis. Height and weight observations at lower and upper extremes were compared with other values recorded in the patient chart and were removed when found to be in error. Weight values that changed more than $15 \%$ within a 30 -day timeframe were also compared with other recorded weights to remove erroneous observations. Errors were noted in fewer than $2 \%$ of the weight and height observations. Patients were stratified into BMI groups as defined by the WHO: underweight (BMI, $<18.5 \mathrm{~kg} / \mathrm{m}^{2}$ ), normal weight (BMI, 18.5 to $<25$ $\mathrm{kg} / \mathrm{m}^{2}$ ), overweight $\left(\right.$ BMI, 25 to $<30 \mathrm{~kg} / \mathrm{m}^{2}$ ), and obese $\left(\mathrm{BMI}, \geq 30 \mathrm{~kg} / \mathrm{m}^{2}\right) .{ }^{26}$ Age at diagnosis was measured as a continuous variable in all Cox models.

Presence or absence of B symptoms ( unexplained fevers, drenching night sweats, or weight loss of $>10 \%$ of baseline weight within 6 months of diagnosis) was recorded by the VHA central cancer registry for 2,070 (85\%) of 2,430 patients with stage information. Review of electronic medical records identified the presence or absence of B symptoms in 269 (74\%) of 360 patients

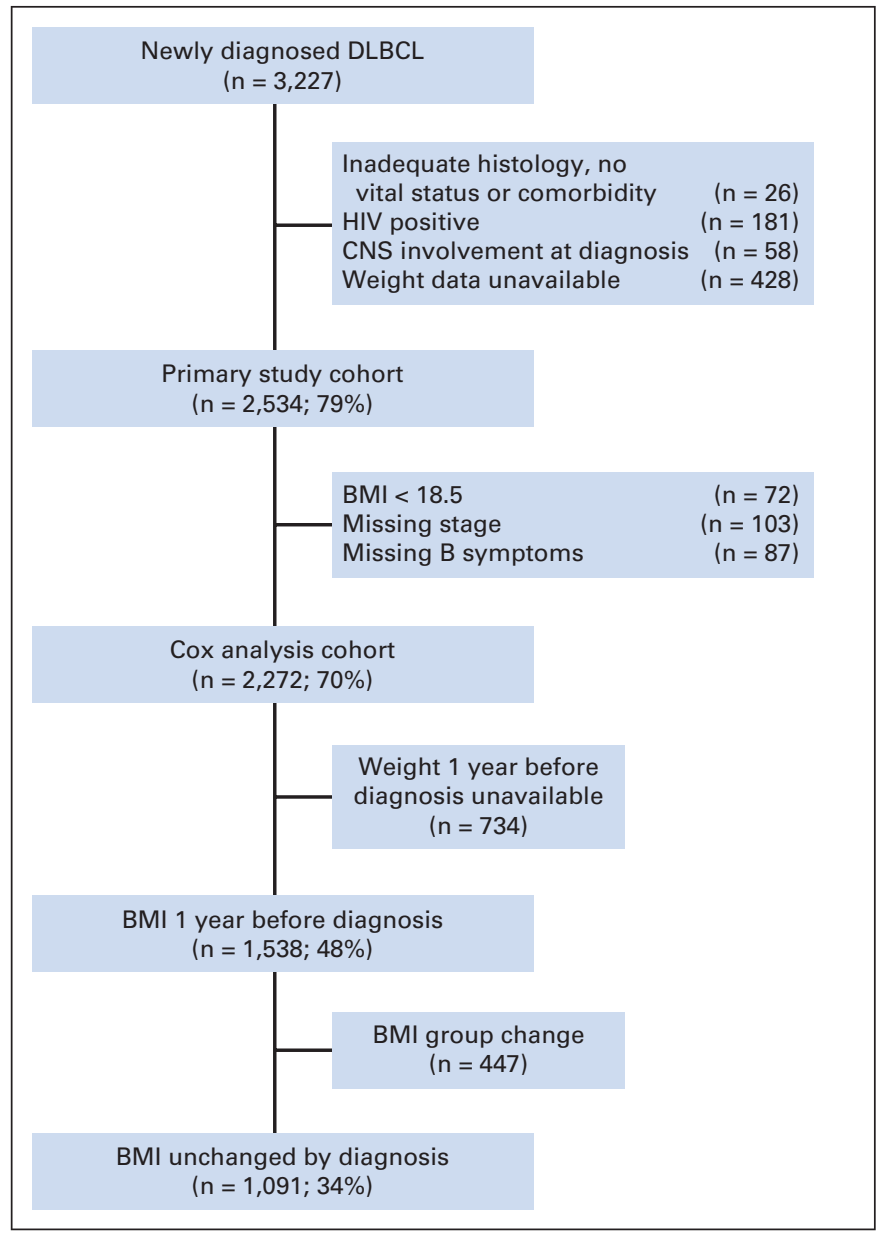

Fig 1. CONSORT diagram for US veterans diagnosed with diffuse large B-cell lymphoma (DLBCL) between 1998 and 2008. BMI, body mass index.

missing B symptom data in the cancer registry. Furthermore, 109 patients classified as B symptom negative in the cancer registry were reclassified as B symptom positive when they were noted to have lost more than $10 \%$ of body weight in the 6 months before diagnosis. In total, B symptom and stage data were obtained in 2,339 (92\%) of 2,534 patients in the primary cohort.

Comorbid conditions were identified using ICD-9 codes recorded at the time of DLBCL diagnosis. The Romano adaptation of the Charlson comorbidity index was calculated using ICD-9 codes. $^{27}$

The prerituximab era was defined as the period from October 1, 1998 through January 31,2002 and the rituximab era was defined as the period from February 1, 2002 onward, related to publication of the landmark study by Coiffier et $\mathrm{al}^{28}$ demonstrating that rituximab improved survival in DLBCL patients. Rituximab era was then used as a surrogate measure of rituximab treatment.

\section{Statistical Analyses}

$\chi^{2}$, Cochrane-Mantel-Haenszel, and one-way analysis of variance tests were used for univariate analyses, where appropriate. A two-tailed $\alpha$ significance level of .05 was considered statistically significant. An $\alpha$ significance level of .1 suggested a trend, and identified variables for inclusion in multivariate analyses. Survival was estimated using the Kaplan-Meier method, with statistical comparison using the log-rank statistic. Patients who did not have date of death information were assumed to be alive at the time of last recorded death within the cohort, an assumption supported by a previous work demonstrating that greater than $97 \%$ of death events are captured in the VHA vital status files. ${ }^{29,30}$ 
Cox proportional hazards regression models were used to assess the association of BMI and survival while controlling for variables identified during univariate analyses. Cox modeling utilized patients with $\mathrm{BMI} \geq 18.5$ and complete clinical information for all variables, leaving a cohort of 2,272. Additional Cox analyses were performed on those with historical weight information ( 1 year before diagnosis). These data were available for 1,538 of 2,272 patients with complete information on covariates and BMI $\geq 18.5$. Of 1,538 patients with historical weight information, 1,091 did not gain or lose sufficient weight to change BMI group by the time of diagnosis and were analyzed separately. The proportional hazards assumption was tested using Schoenfeld residuals and by insertion of time dependent covariates. All statistical analyses were performed using SAS version 9.2 (SAS Institute, Cary, NC).

\section{RESULTS}

Baseline characteristics of the study cohort are listed in Table 1. Median survival times were 33.1 months for the entire cohort, 7.2 months in underweight, 16.4 months in normal weight, and 39.7 months in overweight patient groups. Median survival time was not reached for the obese group. Consistent with the general population, $64 \%$ of all patients were classified as overweight $(39 \%)$ or obese $(25 \%)$ at the time of diagnosis. Mean age of the entire cohort was 68 years (range, 20 to 100). Mean age in the obese BMI group was significantly younger

Table 1. Demographic and Clinical Characteristics Stratified by BMI Among US Veterans Diagnosed With DLBCL From 1998 to 2008

\begin{tabular}{|c|c|c|c|c|c|c|}
\hline Characteristic & Overall & $\begin{array}{l}<18.5 \\
(n=72)\end{array}$ & $\begin{array}{c}18.5 \text { to } \\
<25 \\
(n=849)\end{array}$ & $\begin{array}{c}25 \text { to } \\
<30 \\
(n=988)\end{array}$ & $\begin{array}{c}\geq 30 \\
(n=625)\end{array}$ & $P^{*}$ \\
\hline \multicolumn{7}{|l|}{ Age, years } \\
\hline Mean & 67.6 & 70.7 & 68.7 & 68.4 & 64.5 & $<.001 \dagger$ \\
\hline$>60, \%$ & 70.2 & 73.6 & 72.1 & 73.7 & 61.8 & $<.001 \neq$ \\
\hline Sex, \% & & & & & & $.865 \S$ \\
\hline Male & 97.4 & 95.8 & 97.2 & 97.5 & 97.6 & \\
\hline Race, \% & & & & & & $.589 \S$ \\
\hline White & 88.4 & 84.7 & 87.2 & 89.3 & 89.0 & \\
\hline Black & 9.1 & 13.9 & 10.3 & 8.1 & 8.5 & \\
\hline Other & 2.6 & 1.4 & 2.6 & 2.6 & 2.6 & \\
\hline Stage, \% & & & & & & $.092 \ddagger$ \\
\hline I & 23.8 & 26.4 & 23.6 & 23.0 & 25.3 & \\
\hline II & 16.5 & 12.5 & 14.7 & 17.2 & 18.4 & \\
\hline III & 19.1 & 13.9 & 17.6 & 19.2 & 21.6 & \\
\hline IV & 36.4 & 45.8 & 38.5 & 36.6 & 32.2 & \\
\hline Missing & 4.1 & 1.4 & 5.7 & 4.0 & 2.6 & \\
\hline \multicolumn{7}{|l|}{$\begin{array}{l}\text { Mean comorbidity } \\
\text { (Charlson) }\end{array}$} \\
\hline score & 2.4 & 2.9 & 2.2 & 2.5 & 2.5 & $.014 \dagger$ \\
\hline Mean weight, kg & 84.9 & 54.1 & 70.1 & 85.7 & 107.4 & $<.001 \dagger$ \\
\hline Mean height, cm & 176.9 & 178.4 & 176.4 & 177.0 & 177.2 & $.109+$ \\
\hline B symptoms, \% & & & & & & $<.001 \S$ \\
\hline Yes & 45.1 & 66.7 & 49.5 & 45.2 & 36.3 & \\
\hline No & 50.0 & 26.4 & 45.0 & 50.1 & 59.2 & \\
\hline Missing & 5.0 & 7.0 & 5.5 & 4.7 & 4.5 & \\
\hline Rituximab era, \% & 80.8 & 73.6 & 80.2 & 80.8 & 82.6 & $.505 \S$ \\
\hline $\begin{array}{l}\text { Five-year } \\
\quad \text { mortality, No. }\end{array}$ & 1,436 & 55 & 541 & 546 & 294 & $<.001 \S$ \\
\hline
\end{tabular}

Abbreviations: ANOVA, analysis of variance; BMI, body mass index; DLBCL, diffuse large B-cell lymphoma.

${ }^{*}$ Univariate analyses restricted to $\mathrm{BMI}>=18.5$.

tANOVA F-test.

¥Cochran-Mantel-Haenszel (nonzero correlation) test. $\S \chi^{2}$ test. than that in the normal weight and overweight groups. The mean Charlson score was 2.4, with overweight and obese patients having a higher score than normal weight patients. B symptoms were more frequent in the normal weight and overweight groups compared with the obese group.

To address concerns of bias, comparisons were made between patients with $(\mathrm{n}=2,534)$ and without $(\mathrm{n}=428)$ weight measurements at diagnosis (Appendix Table A1, online only). On KaplanMeier analysis, no significant survival differences were noted between patients with and without weight data.

In 2010 , the VHA patient population was $80.7 \%$ white, $11.6 \%$ black, $6 \%$ women, and $45 \%$ older than 65 years. ${ }^{31}$ After accounting for demographic changes during the study timeframe and the lower incidence of DLBCL in younger patients, women, and minorities, the study population approximates the overall VHA patient population. ${ }^{31,32}$ Because the cohort is largely white men, additional data and analyses on this patient subset are provided in Appendix Tables A2 and A3 (online only).

Kaplan-Meier analysis of the primary study cohort stratified by BMI at diagnosis demonstrated increased mortality in the underweight BMI group, whereas the overweight and obese BMI groups had decreased mortality compared with the normal weight group (Fig 2). Underweight patients were excluded from further analyses because of small numbers. For each level of BMI, the estimated 3-year survival probabilities were computed across patients within the study cohort and then plotted against BMI as a continuous variable with associated 95\% CI (Fig 3).

Cox modeling compared overall survival across BMI groups while controlling for age, stage, comorbidities, and B symptoms. The effect of B symptoms and stage varied during the early and late follow-up periods. Hazard ratios (HR) associated with B symptoms and stage were therefore stratified into early ( 0 to 2 months) and late ( $>2$ months) timeframes to meet the proportional hazards assumption. Interactions between BMI and other variables were tested through insertion of interaction variables into the Cox model and none were significant (BMI and age: $\chi^{2}=1.96 ; P=.37$; BMI and $\mathrm{B}$ symptoms: $\chi^{2}=1.62 ; P=.45$; BMI and comorbidity score: $\chi^{2}=1.45$; $P=.49 ; \mathrm{BMI}$ and stage; $\left.\chi^{2}=10.09 ; P=.12\right)$. In the Cox analysis, overweight and obese patients had lower mortality compared with normal weight patients ( $\mathrm{HR}, 0.73$; $95 \% \mathrm{CI}, 0.65$ to 0.83 ; and $\mathrm{HR}, 0.68$;

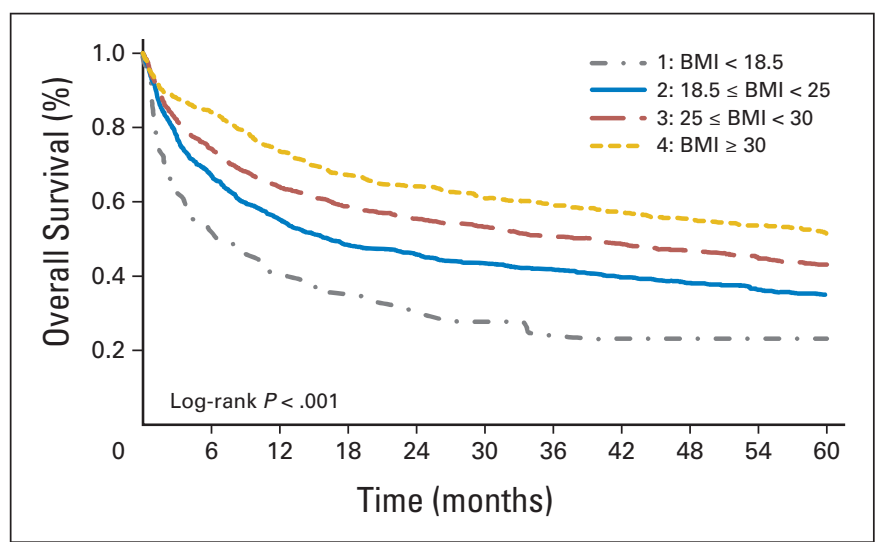

Fig 2. Kaplan-Meier curves of US veterans diagnosed with diffuse large B-cell lymphoma from 1998 to 2008, body mass index (BMI) at diagnosis, and overall survival $(\mathrm{n}=2,534)$. Log-rank $P<.001$. 


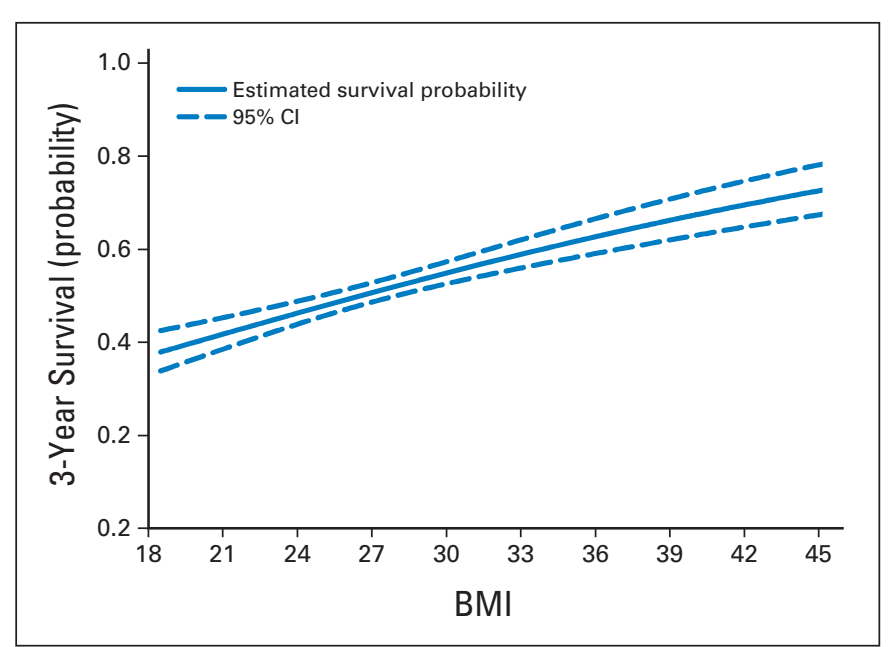

Fig 3. Estimated 3-year survival probability among US veterans diagnosed with diffuse large B-cell lymphoma from 1998 to 2008, based on body mass index (BMI) at time of diagnosis.

95\% CI, 0.58 to 0.80 , respectively). Hazard ratios for all variables are listed in Table 2. A second Cox analysis was performed to control for treatment during the rituximab era. Although treatment in the rituximab era was independently associated with lower mortality (HR, 0.73; 95\% CI, 0.63 to 0.83 ), the protective association of elevated BMI was unchanged (HR for overweight, $0.73 ; 95 \% \mathrm{CI}, 0.64$ to 0.83 ; and HR for obese, 0.68 ; $95 \%$ CI, 0.59 to 0.8 ).

To ensure that disease-related weight loss in the lower BMI groups was not driving differences in overall survival, patients with historical weight data (measured 1 year before diagnosis) were identified ( $\mathrm{n}=1,538)$. This subgroup of patients was older (median age, 71 years) and had a higher comorbidity score (mean, 2.9) compared with the primary study cohort in Table 1 . When stratified by historic BMI

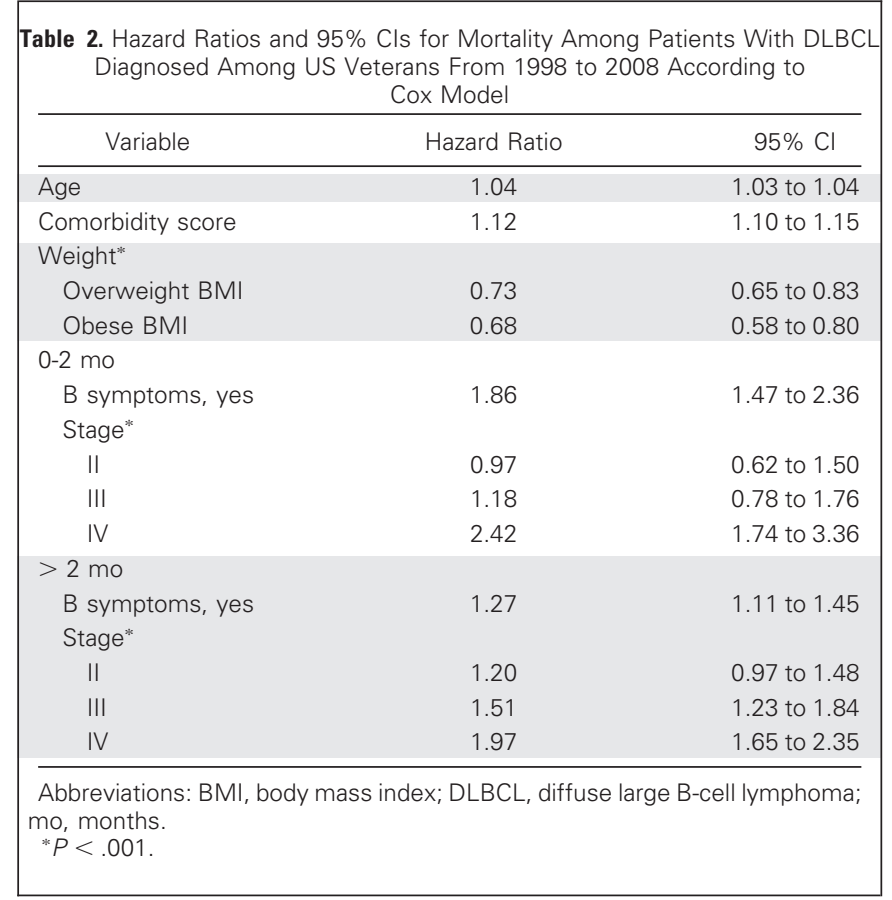

(before disease-related weight loss) there was no difference in B symptom frequency between BMI groups. Of 1,538 patients with historical weight information, 447 patients (29\%) were reclassified into a lower BMI category by the time of diagnosis. Cox analysis stratified by historical BMI continued to demonstrate decreased mortality in the overweight (HR, 0.76; 95\% CI, 0.64 to 0.91 ) and obese (HR, 0.76; 95\% CI, 0.64 to 0.91 ) BMI groups.

The subset of patients with weight measured 1 year before diagnosis who did not change BMI group by the time of diagnosis ( $\mathrm{n}=1,091)$ were next evaluated. Cox analysis on this group again showed decreased mortality in the overweight (HR, 0.66; 95\% CI, 0.54 to 0.81 ) and obese (HR, $0.7 ; 95 \% \mathrm{CI}, 0.56$ to 0.87 ) groups. The persistent inverse association between BMI and mortality supports the conclusion that the association between obesity and survival is independent of disease-related weight loss.

To understand the timeframe during which survival differences between BMI groups (measured at diagnosis) manifest, an adjusted Cox analysis was performed with hazard ratios measured for the time periods of up to 6 months and 6 to 60 months after diagnosis. Although the magnitude of the BMI association was greater in the first 6 months (overweight group $\mathrm{HR}, 0.69 ; 95 \% \mathrm{CI}, 0.58$ to 0.83 ; obese group HR, 0.53 ; 95\% CI, 0.41 to 0.68 ) compared with 6 months to 5 years after diagnosis (overweight group HR, 0.78; 95\% CI, 0.65 to 0.93; obese group HR, 0.81 ; $95 \%$ CI, 0.66 to 0.98$)$, the findings maintained significance in both time periods.

Information on international prognostic index (IPI) ${ }^{33}$ was obtained on 492 patients (20\%) of the primary study cohort between the years 2004 and 2008. The IPI was significantly higher in the underweight group compared with the obese group, and no other comparisons were significant.

\section{DISCUSSION}

In this cohort of largely white male veterans with DLBCL, overweight or obese BMI at the time of diagnosis was associated with improved overall survival. Because significant survival differences were noted both at 6 months after diagnosis and from 6 months to 5 years after diagnosis, this observation is not exclusively related to differences in treatment-related mortality. Improved survival was also noted when patients were stratified by BMI 1 year before diagnosis, suggesting that disease-related weight loss was not simply causing migration of poorer prognosis patients into the normal BMI group and reverse causation bias.

There are several potential mechanisms whereby increased BMI could improve survival in DLBCL. Better treatment tolerance could result in higher chemotherapy dose intensity in heavier patients with an elevated BMI, resulting in improving survival. ${ }^{34}$ However, the frequent use of empiric dose reduction in obese cancer patients suggests that overweight and obese DLBCL patients may actually receive lower relative chemotherapy doses. ${ }^{7}$ Differences in pharmacokinetics between the obese and nonobese could result in a higher physiologic chemotherapy dose in the obese. However, a previous study found that doxorubicin clearance was reduced in obese women but not men, arguing against this mechanism in this cohort. ${ }^{35}$ It is also conceivable that obesity may preferentially drive development of germinal center phenotype disease in the overweight and obese, which in turn would 
be associated with a better prognosis. ${ }^{36,37}$ Testing of these hypotheses will require further study.

Most studies of obesity and NHL measure BMI near the time of NHL diagnosis. Our finding that $29 \%$ of the patients lost enough weight to change BMI category by the time of diagnosis highlights that care must be taken whenever the relationship between BMI and NHL is evaluated. Future studies should consider patient weight 1 year or more before NHL diagnosis. Failure to do so will underestimate the impact of BMI as a result of disease-related weight loss.

Although the mean age of obese patients was lower than the other BMI groups, in the absence of treatment, DLBCL results in death within months. Thus, the observed age difference of 4 years cannot be explained by increased medical surveillance and earlier disease detection in the obese, arguing against residual lead-time bias. Among patients with weight information 1 year before DLBCL diagnosis, obese patients were still significantly younger than overweight and normal weight patients (mean age, 67.1, 70.3, and 71.3 years respectively; $P<.001$ ), further supporting this finding. Thus, it seems that for unknown reasons, obese patients tend to be a younger mean age at diagnosis than nonobese patients, just as black patients are diagnosed at a younger mean age compared with white patients. ${ }^{38}$

In a posthoc analysis, age was measured as a dichotomous variable ( $>60$ years $v \leq 60$ years), similar to the IPI. Overweight and obese patients older than 60 years demonstrated significantly decreased mortality (HR, 0.7 ; 95\% CI, 0.61 to 0.8 and HR, 0.55 ; 95\% CI, 0.46 to 0.66 , respectively). Decreased mortality was also observed in overweight and obese patients $\leq 60$ years old, though the effect was no longer significant in this subgroup (HR, 0.81; 95\% CI, 0.6 to 1.09 and HR, $0.85 ; 95 \%$ CI, 0.63 to 1.15 , respectively), likely owing in part to the smaller sample size and reduced statistical power. Interpretation of these findings should be approached with caution.

Strengths of this study include the large number of patients and diversity of treatment centers within the VHA system, which are located throughout the United States. As a study based on the population of veterans receiving health benefits through the VHA, patients also had an equal opportunity for inclusion regardless of comorbidities or other factors that may limit enrollment in therapeutic clinical trials. The VHA provides treatment regardless of insurance status, removing health insurance coverage as a potential confounder. Finally, the VHA has detailed and accurate records on overall survival, as described in Patients and Methods.

There are also limitations that should be noted. The VHA largely serves individuals who served in the United States military, the majority of whom are men who at one time also met the physical requirements of military service. As a result, it is possible that the veteran population may have a lower proportion of body fat at each BMI level, compared with the general population. The median income of the VHA population is also lower than that of the general population. These factors limit the ability to extrapolate these findings to the entire DLBCL patient population. Information on the IPI was not collected in all members of the study cohort. Comparison of the patients in whom IPI information was available did not demonstrate significant differences between normal, overweight, and obese BMI groups, but a BMI-related difference could still be present. Finally, it is conceivable that residual confounding is present owing to variables that were unknown or unmeasured, such as treatment selection and treatment dose intensity.

Obesity at the time of cancer diagnosis is associated with decreased survival in some malignancies and improved survival in others, including DLBCL. Further work will be required to understand the mechanisms responsible for this observation in DLCBL and their relation to DLBCL treatment. Understanding the mechanisms responsible for improved survival in DLBCL and other malignancies may help optimize therapy in obese and nonobese cancer patients.

\section{AUTHORS' DISCLOSURES OF POTENTIAL CONFLICTS OF INTEREST}

Although all authors completed the disclosure declaration, the following author(s) and/or an author's immediate family member (s) indicated a financial or other interest that is relevant to the subject matter under consideration in this article. Certain relationships marked with a " $U$ " are those for which no compensation was received; those relationships marked with a " $C$ " were compensated. For a detailed description of the disclosure categories, or for more information about ASCO's conflict of interest policy, please refer to the Author Disclosure Declaration and the Disclosures of Potential Conflicts of Interest section in Information for Contributors. Employment or Leadership Position: None Consultant or Advisory Role: None Stock Ownership: None Honoraria: Kenneth R. Carson, Genentech Research Funding: None Expert Testimony: None Other Remuneration: None

\section{AUTHOR CONTRIBUTIONS}

Conception and design: Kenneth R. Carson, Jay R. McDonald, Graham A. Colditz

Financial support: Kenneth R. Carson, Graham A. Colditz

Administrative support: Graham A. Colditz

Collection and assembly of data: Kenneth R. Carson, Suhong Luo, Angelique Zeringue

Data analysis and interpretation: All authors

Manuscript writing: All authors

Final approval of manuscript: All authors

\section{REFERENCES}

1. Flegal KM, Carroll MD, Ogden $C L$, et al: Prevalence and trends in obesity among US adults, 1999-2008. JAMA 303:235-241, 2010

2. Berrington de Gonzalez A, Hartge P, Cerhan JR, et al: Body-mass index and mortality among 1.46 million white adults. N Engl J Med 363:2211-2219, 2010

3. Jee SH, Sull JW, Park J, et al: Body-mass index and mortality in Korean men and women. N Engl J Med 355:779-787, 2006
4. Adams KF, Schatzkin A, Harris TB, et al: Overweight, obesity, and mortality in a large prospective cohort of persons 50 to 71 years old. N Engl J Med 355:763-778, 2006

5. Calle EE, Rodriguez C, Walker-Thurmond K, et al: Overweight, obesity, and mortality from cancer in a prospectively studied cohort of U.S. adults. N Engl J Med 348:1625-1638, 2003

6. Wolin KY, Carson K, Colditz GA, et al: Obesity and cancer. Oncologist 15:556-565, 2010

7. Griggs JJ, Sorbero ME, Lyman GH, et al: Undertreatment of obese women receiving breast cancer chemotherapy. Arch Intern Med 165:12671273, 2005

8. Han $X$, Zheng $T$, Foss $F$, et al: Vegetable and fruit intake and non-Hodgkin lymphoma survival in Connecticut women. Leuk Lymphoma 51:10471054, 2010

9. Courneya KS, Sellar CM, Stevinson C, et al: Randomized controlled trial of the effects of aerobic exercise on physical functioning and quality of life in lymphoma patients. J Clin Oncol 27:4605-4612, 2009

10. Chlebowski RT, Blackburn GL, Thomson CA, et al: Dietary fat reduction and breast cancer outcome: 
Interim efficacy results from the Women's Intervention Nutrition Study. J Natl Cancer Inst 98:17671776, 2006

11. Holmes MD, Chen WY, Feskanich D, et al: Physical activity and survival after breast cancer diagnosis. JAMA 293:2479-2486, 2005

12. Dignam JJ, Polite BN, Yothers G, et al: Body mass index and outcomes in patients who receive adjuvant chemotherapy for colon cancer. J Nat Cancer Inst 98:1647-1654, 2006

13. Ewertz $M$, Jensen $M B$, Gunnarsdóttir KA, et al: Effect of obesity on prognosis after early-stage breast cancer. J Clin Oncol 29:25-31, 2011

14. Sinicrope FA, Dannenberg AJ: Obesity and breast cancer prognosis: Weight of the evidence. J Clin Oncol 29:4-7, 2011

15. Bastarrachea J, Hortobagyi GN, Smith TL, et al: Obesity as an adverse prognostic factor for patients receiving adjuvant chemotherapy for breast cancer. Ann Intern Med 120:18-25, 1994

16. Calle EE, Kaaks R: Overweight, obesity and cancer: Epidemiological evidence and proposed mechanisms. Nat Rev Cancer 4:579-591, 2004

17. Lopes-Serrao MD, Ussery SM, Hall RG II, et al: Evaluation of chemotherapy-induced severe myelosuppression incidence in obese patients with capped dosing. J Oncol Pract 7:13-17, 2011

18. Waalkes S, Merseburger AS, Kramer MW, et al: Obesity is associated with improved survival in patients with organ-confined clear-cell kidney cancer. Cancer Causes Control 21:1905-1910, 2010

19. Yang $R$, Cheung MC, Pedroso FE, et al: Obesity and weight loss at presentation of lung cancer are associated with opposite effects on survival. J Surg Res 170:e75-e83, 2011

20. Landgren $\mathrm{O}$, Andrén $\mathrm{H}$, Nilsson $\mathrm{B}$, et al: Risk profile and outcome in Hodgkin's lymphoma: Is obesity beneficial? Ann Oncol 16:838-840, 2005
21. Geyer SM, Morton LM, Habermann TM, et al: Smoking, alcohol use, obesity, and overall surviva from non-Hodgkin lymphoma: A population-based study. Cancer 116:2993-3000, 2010

22. Jones JA, Fayad LE, Elting LS, et al: Body mass index and outcomes in patients receiving chemotherapy for intermediate-grade B-cell non-Hodgkin lymphoma. Leuk Lymphoma 51:1649-1657, 2010

23. Tarella C, Caracciolo D, Gavarotti $P$, et al: Overweight as an adverse prognostic factor for non-Hodgkin's lymphoma patients receiving highdose chemotherapy and autograft. Bone Marrow Transplant 26:1185-1191, 2000

24. Navarro WH, Loberiza FR Jr, Bajorunaite $R$, et al: Effect of body mass index on mortality of patients with lymphoma undergoing autologous hematopoietic cell transplantation. Biol Blood Marrow Transplant 12:541-551, 2006

25. Morton LM, Turner JJ, Cerhan JR, et al: Proposed classification of lymphoid neoplasms for epidemiologic research from the Pathology Working Group of the International Lymphoma Epidemiology Consortium (InterLymph). Blood 110:695-708, 2007

26. World Health Organization: Global Database on Body Mass Index. http://apps.who.int/bmi/ index.jsp?introPage =intro_3.html (Accessed July 17, 2011)

27. Romano PS, Roos LL, Jollis JG: Adapting a clinical comorbidity index for use with ICD-9-CM administrative data: Differing perspectives. J Clin Epidemiol 46:1075-1079, 1993; discussion 81-90

28. Coiffier B, Lepage E, Briere J, et al: CHOP chemotherapy plus rituximab compared with $\mathrm{CHOP}$ alone in elderly patients with diffuse large-B-cell Iymphoma. N Engl J Med 346:235-242, 2002

29. Savas LS, del Junco DJ, Bastian LA, et al: Mortality ascertainment of women veterans: A comparison of sources of vital status information, 19792002. Med Care 47:125-128, 2009
30. Sohn M, Arnold N, Maynard C, et al: Accuracy and completeness of mortality data in the Department of Veterans Affairs. Popul Health Metr 4:2, 2006

31. US Department of Veterans Affairs, Veterans Health Administration: 2010 Survey of Veteran Enrollees' Health and Reliance Upon VA. http:// www.va.gov/HEALTHPOLICYPLANNING/Soe2010/ SoE_2010_Final.pdf

32. Morton LM, Wang SS, Devesa SS, et al: Lymphoma incidence patterns by WHO subtype in the United States, 1992-2001. Blood 107:265-276, 2006

33. The International Non-Hodgkin's Lymphoma Prognostic Factors Project: A predictive model for aggressive non-Hodgkin's lymphoma. N Engl J Med 329:987-994, 1993

34. Bosly A, Bron D, Van Hoof A, et al: Achievement of optimal average relative dose intensity and correlation with survival in diffuse large B-cell lymphoma patients treated with $\mathrm{CHOP}$. Ann Hematol 87:277-283, 2008

35. Sparreboom A, Wolff AC, Mathijssen RH, et al: Evaluation of alternate size descriptors for dose calculation of anticancer drugs in the obese. J Clin Oncol 25:4707-4713, 2007

36. Renehan AG, Tyson M, Egger M, et al: Bodymass index and incidence of cancer: A systematic review and meta-analysis of prospective observational studies. Lancet 371:569-578, 2008

37. Rosenwald A, Wright G, Chan WC, et al: The use of molecular profiling to predict survival after chemotherapy for diffuse large-B-cell lymphoma. N Engl J Med 346:1937-1947, 2002

38. Shenoy PJ, Malik N, Nooka A, et al: Racial differences in the presentation and outcomes of diffuse large B-cell lymphoma in the United States. Cancer 117:2530-2540, 2011 